\title{
High Expression of Methionine Aminopeptidase Type 2 in Germinal Center B Cells and Their Neoplastic Counterparts
}

\author{
Takayuki Kanno, Hideya Endo, Kengo Takeuchi, Yasuyuki Morishita, \\ Masashi Fukayama, and Shigeo Mori \\ Division of Pathology (TK, HE, SM), Institute of Medical Science, and Department of Pathology (KT, YM, MF), \\ Faculty of Medicine, University of Tokyo, Tokyo, Japan
}

\begin{abstract}
SUMMARY: Methionine aminopeptidase type 2 (MetAP2) is a bifunctional protein that plays critical roles in the regulation of protein synthesis and post-translational processing by (a) protecting the alpha subunit of eukaryotic initiation factor 2 from inhibitory phosphorylation by eukaryotic initiation factor 2 kinases and (b) removing the amino-terminal methionine residue from nascent protein. MetAP2 is also known as the molecular target of the angiogenesis inhibitor TNP-470. In addition, it has been recently suggested that MetAP2 has an antiapoptotic function in mesothelioma. To know the pattern of expression of MetAP2 in normal and neoplastic tissues, we raised two specific rabbit polyclonal Abs and examined the pattern of MetAP2 expression in various normal and pathologic specimens. Unexpectedly, we found a very high and selective expression of MetAP2 in germinal center B cells. In the germinal center, dark zone B cells tended to express more MetAP2 than light zone B cells. When 200 malignant lymphomas of various subtypes were studied, a high level of MetAP2 expression, equivalent to that observed in germinal center B cells, was noted exclusively on B-cell lymphoma subtypes that are currently regarded as the neoplastic counterparts of germinal center B cells. The expression of MetAP2 in diffuse large B-cell lymphomas correlated well with that of BCL6 $(p<0.05)$ but not with that of either CD10 or BCL2. These data suggest that MetAP2 has specific function(s) in germinal center B cells and that the function is shared by neoplastic counterparts of germinal center B cells. (Lab Invest 2002, 82:893-901).
\end{abstract}

$M$ ethionine aminopeptidase (MetAP) is an enzyme that was initially shown to remove the $\mathrm{N}$-terminal methionine residue from proteins at the initial phase of translation. The translation process on ribosomes is known to start with methionine, and the $\mathrm{N}$-terminal methionine is usually removed before the newly synthesized protein is transported to its proper intracellular locus (Flinta et al, 1986). The existence of a specific enzyme that is responsible for the removal of the N-terminal methionine, termed as aminopeptidase, was first postulated in 1970 (Jackson and Hunter, 1970; Kerwar et al, 1971; Wigle and Dixon, 1970), and the aminopeptidase gene was first cloned by Ben-Bassat et al (1987) in Escherichia coli. Since then, the MetAP2 cDNA sequences from several species, including humans, have been clarified (Arfin et al, 1995; Chang et al, 1992; Li and Chang, 1995a, 1995b; Movva et al, 1990). In eukaryotes, two types of MetAPs, types I and II (MetAP1 and MetAP2, respectively), have been identified using amino acid se-

\section{DOI: 10.1097/01.LAB.0000020419.25365.C4}

Received February 4, 2002.

This research was supported by a Grant-in-Aid for Scientific Research on Priority Areas from the Japanese Ministry of Education, Science, and Culture.

Address reprint requests to: Dr. Takayuki Kanno, Division of Pathology, Institute of Medical Science, University of Tokyo, 4-6, Shirokanedai, Minato-ku, Tokyo 108-8639, Japan.E-mail: jtakayuk-tky@umin.ac.jp quence analysis. MetAP2 is distinguished from MetAP1 by the addition of a helical subdomain of approximately 60 residues that is inserted within the C-terminal domain of the former (Arfin et al, 1995; Bradshaw et al, 1998; Lowther and Matthews, 2000).

Another known function of MetAP2 is the protection of eukaryotic initiation factor 2 alpha subunit (elF2- $\alpha$ ) from inhibitory phosphorylation (Datta et al, 1988; Li and Chang, 1996). The elF2 is a protein complex that is responsible for rate limitation of mRNA translation. The elF2 protein binds with guanosine triphosphate (GTP) and Met-tRNA during mRNA translation, and the resulting elF2/GTP/Met-tRNA complex induces the transfer of Met-tRNA to a $40 \mathrm{~S}$ ribosomal subunit. It has been shown that the phosphorylation of elF2- $\alpha$ prevents formation of the elF2/GTP/Met-tRNA complex, resulting in inhibition of global protein synthesis. In its active state, elF2- $\alpha$ can be phosphorylated at residue Ser51 by elF2- $\alpha$ kinases, whereas MetAP2, by binding to elF2- $\alpha$, protects this site from phosphorylation (Datta, 2000; Kimball, 1999; Pestova et al, 2001).

Recently, it has been suggested that MetAP2 is associated with angiogenesis: fumagillin, ovalicin, and TNP-470 are potent angiogenesis inhibitors and are thought to bind to MetAP2, causing blocking of the endothelial cell cycle at the late G1 phase (Griffith et al, 1997; Liu et al, 1998; Sin et al, 1997; Zhang et al, 2000). On binding with these substances, the MetAP activity of MetAP2 is abolished, although the ability to 
block the phosphorylation of elF2- $\alpha$ by elF2 kinases remains intact (Griffith et al, 1997).

In addition, Catalano et al (2001) suggested that MetAP2 was involved in apoptosis in mesothelioma. Their article suggests that high expression of MetAP2 in mesothelioma resulted in prevention of apoptosis. They also suggested that BCL2 was involved in this preventive mechanism.

S100A4 is a calcium-binding protein that is thought to play roles in experimental tumor metastasis. We recently found a molecular association between S100A4 and MetAP2 (Endo et al, 2002). In an attempt to reveal the expression of MetAP2 in normal and neoplastic cells, we developed two Abs that react specifically with different epitopes of MetAP2. While investigating the localization of MetAP2 in various human tissues, we found marked expression on germinal center B cells and their neoplastic counterparts. The germinal center is the site where B lymphocytes proliferate and undergo terminal differentiation through antigenic stimulation. Specifically, the germinal center is the site where class switching and somatic hypermutation of immunoglobulin genes occur (MacLennan, 1994; McHeyzer-Williams et al, 2001). Here, a large portion of $B$ lymphocytes either lose the ability to bind antigen or fail to produce a functional $A b$ and undergo apoptosis. During this process, peculiar expression profiles of various proteins are observed, such as low expression of the BCL2 protein and high expression of BCL6, CD10, CD40, A-myb, DNA repair protein, oxoguanine DNA glycosylase, and BOB1 (Golay et al, 1998; Kuppers et al, 1999; Martinez-Valdez et al, 1996; Onizuka et al, 1995; Schubart et al, 1996). However, no previous reports have ever referred to the overexpression of MetAP2 protein in germinal center B cells.

The existing classifications of human malignant lymphoma are based on a combination of histology, immunophenotyping, oncovirus infection status, and genetic abnormalities. Each subtype reflects more or less the normal counterpart in terms of lineage and differentiation level. Lymphomas were classified into 27 subtypes according to the revised EuropeanAmerican lymphoma (REAL) study group classification (Harris et al, 1994) and into 32 subtypes according to the new World Health Organization (WHO) classification (Jaffe et al, 2001). Of these WHO classification subtypes, all follicular lymphomas, half of the diffuse large B-cell lymphomas, and all Burkitt's lymphomas comprise the neoplastic counterparts of normal germinal center B cells. Thus, our next aim was to clarify how the expression level of MetAP2 on normal lymphocytes is reflected in malignant lymphoma subtypes.

\section{Results}

\section{Specificity of Anti-MetAP2 Abs (hMG and hMP Abs)}

We developed two rabbit anti-MetAP2 Abs that are specific for different epitopes. The first Ab, named hMG $A b$, was made by immunization with recombi-

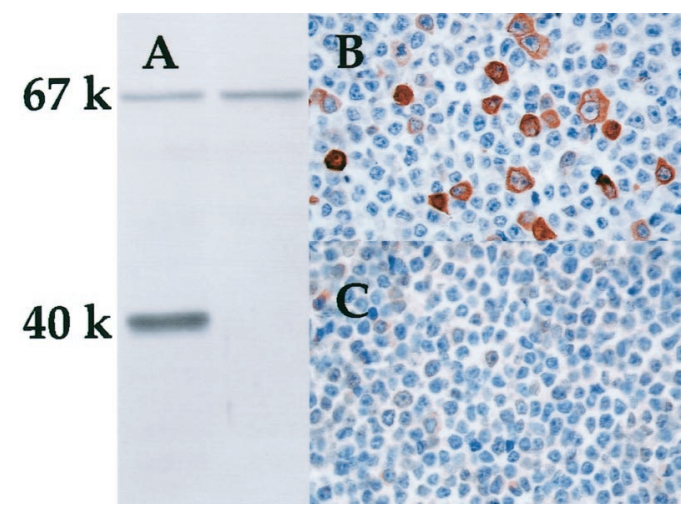

Figure 1.

Characterization of the anti-methionine aminopeptidase type 2 (MetAP2) antibody hMG Ab by immunoblotting and immunostaining. A, Immunoblot analysis of pME18SFLAG hM224-478-transfected 293T cells (left lane) and vector-alone-transfected 293T cells (right lane). B and C, Immunostaining by hMG Ab of pME18SFLAG hM224-478-transfected 293T cells (B) and vectoralone-transfected 293T cells (C). A 67-kDa band corresponding to the full size MetAP2 was observed in both cells, whereas a $40-\mathrm{kDa}$ band corresponding to the C-terminal recombinant protein (FLAG-hM 224-478) was observed exclusively in gene-transfected cells (left). On immunostaining, both heavily and weakly stained gene-transfected cells were observed (B), whereas additional weak staining corresponding to the native MetAP2 protein, was detected in vector-alone-transfected cells (C).

nant protein representing the $\mathrm{C}$-terminal region of MetAP2, corresponding to amino acid residues 224 to 478. The other Ab, named hMP Ab, was made by immunization with synthetic peptide corresponding to amino acid residues 135 to 150 of human MetAP2 (hM135-150). The specificity of these two anti-MetAP2 Abs was then established by immunoblotting and immunohistochemistry. Immunoblotting was performed on lysates obtained from 293T cells into which the plasmid pME18SFLAG alone or the C-terminal portion of the MetAP2 cDNA-inserted plasmid (pME18SFLAG-hM 224-478) was transfected. The $\mathrm{hMG} A \mathrm{~b}$ bound to a band of $67 \mathrm{kDa}$ (corresponding to
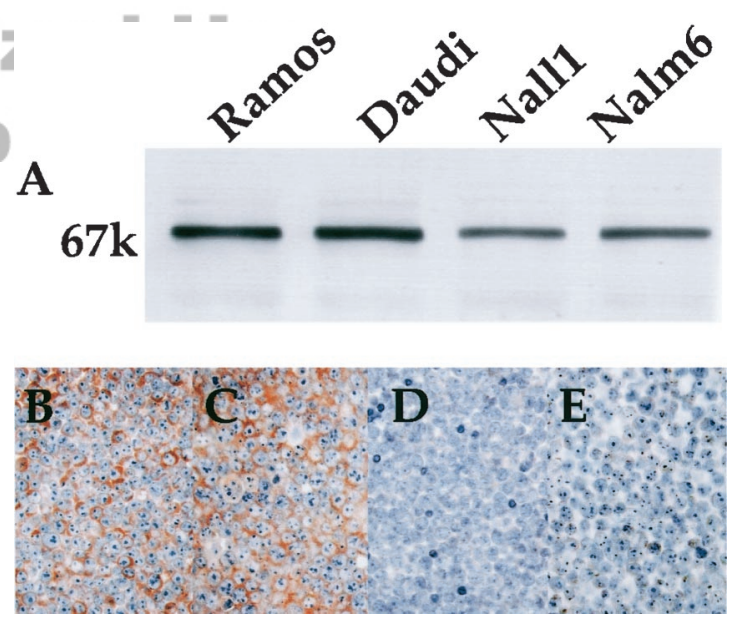

Figure 2.

Correlation between immunoblotting and immunostaining with hMG Ab. A, Immunoblot analysis of MetAP2 expression in four lymphoid cell lines: Ramos, Daudi, Nall1, and Nalm6 using hMG Ab. B, Immunostaining of the four lymphoid cell lines. Levels of MetAP2 protein expression, as revealed by immunoblotting and immunostaining, correspond well. 
the whole MetAP2 molecule) in both transfected cell types and another band of about $40 \mathrm{kDa}$ (corresponding to the FLAG-hM 224-478 recombinant protein) exclusively in pME18SFLAG-hM 224-478-transfected cells (Fig. 1). Immunohistochemistry of the 293T cells into which pME18SFLAG-hM 224-478 had been transfected demonstrated strong staining in some cells and faint staining in some other cells. On the contrary, in cells into which the PME18SFLAG plasmid alone had been introduced, only a weak reaction was noted in some cells (Fig. 1). These results suggest that the $\mathrm{hMG} A \mathrm{~b}$ recognizes both the whole MetAP2 protein (67-kDa band corresponding to the faint staining) and the recombinant protein $(40-\mathrm{kDa}$ band corresponding to the strong staining).

To further confirm the specificity of $\mathrm{hMG} \mathrm{Ab}$ and hMP Ab, four lymphoma cell lines were examined by immunoblotting and immunohistochemistry. The results correlated well with MetAP2 expression, being high in the Burkitt's lymphoma cell lines Ramos and Daudi and low in the precursor non-T non-B lymphoblastic lymphoma cell lines Nall1 and Nalm6 (Fig. 2). Furthermore, immunoprecipitates of 293T cells after treatment with $\mathrm{hMG} A \mathrm{Ab}$ or hMP Ab exhibited identical 67-kDa bands after immunoblotting with another $A b$, suggesting that both Abs recognize the MetAP2 protein specifically (Fig. 3). In the absorption test, the immunoreactivity of hMG Ab was canceled by absorption with an excess amount of GST-hM 224-478 recombinant protein but not with an excess amount of the synthetic peptide hM135-150. Similarly, the immunoreactivity of hMP Ab was canceled by absorption with the synthetic peptide but not by GST-hM 224478. These results indicate clearly that both $\mathrm{hMG}$ and hMP Abs react specifically and independently with MetAP2 protein.

\section{High Expression of MetAP2 Protein in Germinal Center B Cells}

Human tonsils, lymph nodes, and various other organs were immunostained with hMG Ab and hMP Ab. Both of these Abs reacted very heavily with cells located in the germinal centers of tonsils and lymph nodes (Fig. $4, A$ and $B$ ). Heavy staining was observed in more than $70 \%$ of the germinal center cells. In the germinal centers, much heavier staining was noted on cells in the dark zone than in the light zone. The cytoplasm was the main site of staining. Lymphocytes in the mantle zone and the T zone were not stained. A small number of weakly stained cells were observed in the marginal zone and perifollicular areas other than $T$ zones. In addition, tonsillar epithelial cells and endothelial cells were moderately stained.

Most of the epithelial and parenchymal cells in other organs displayed faint to no staining. Among those, weak but definite staining was noted on spermatocytes and spermatids in testis, granulosa cells in ovary, and a small portion of epithelial cells in the collecting tube of the kidney, as is shown in Table 1. It should be noted, however, that the staining intensity
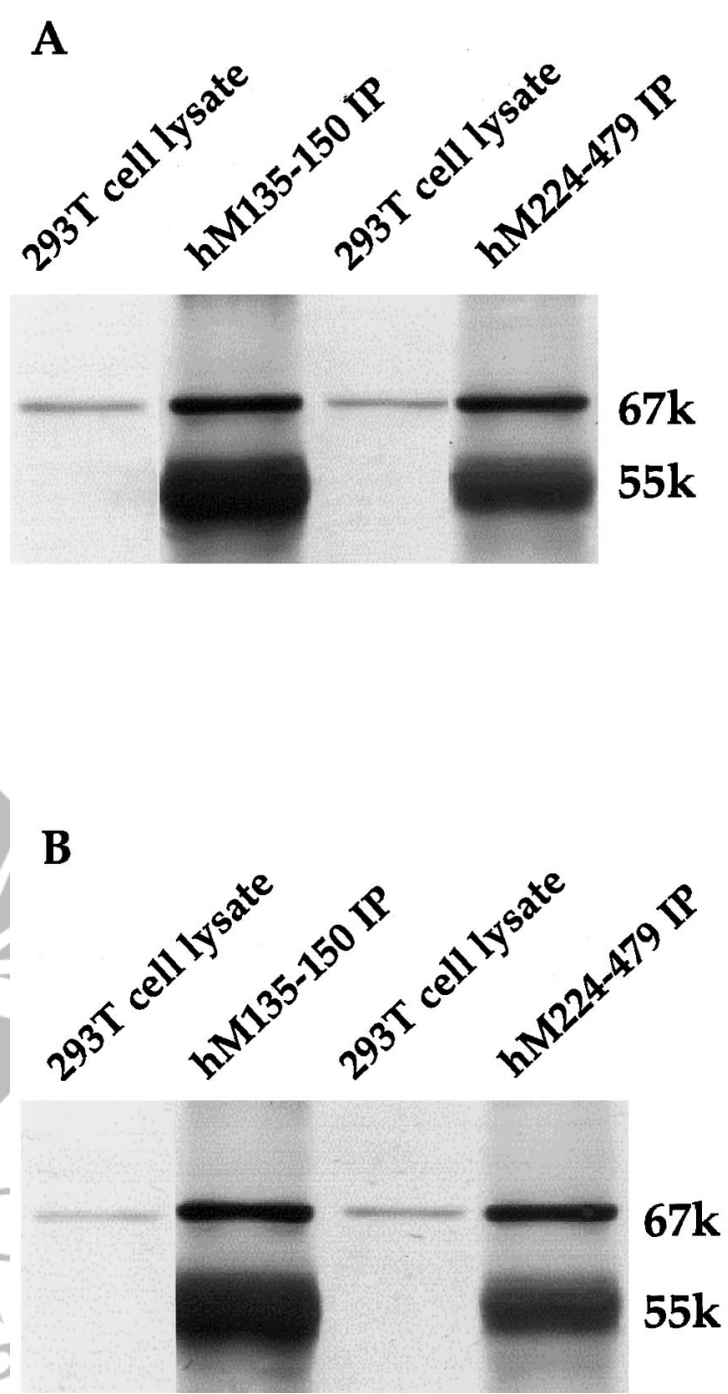

Figure 3.

Comparison between the specificity of immunoprecipitation and immunoblotting of MetAP2 protein by hMG and hMP Abs. Immunoprecipitates prepared from nontransfected 293T cells using hMP Ab (lane 2) and hMG Ab (lane 4) were subjected to immunoblotting with hMP Ab (A) and hMG Ab (B). The immunoprecipitates obtained from 293T cell lysates using these anti-MetAP2 Abs exhibit an identical $67-\mathrm{kDa}$ band after immunoblotting with hMP or hMG Ab. IP = immunoprecipitates.

of these cells was far weaker compared with that of germinal center $B$ cells.

To elucidate the character of the heavily MetAP2stained cells in the germinal centers, double immunolabeling with a combination of $\mathrm{hMG} \mathrm{Ab}$ and anti-CD3, or hMG Ab and anti-CD20 Abs was performed. Very clear colocalization was noted between MetAP2 and CD20 but not between MetAP2 and CD3, clearly demonstrating that $B$ cells but not $T$ cells were the cells stained (Fig. 4C).

\section{Expression of MetAP2 Protein in Lymphomas}

The expression of MetAP2 protein was studied in 200 cases of lymphoma (Table 2). Strong immunostaining, equivalent to that observed in the normal germinal center B cells and categorized as ++ , was observed 

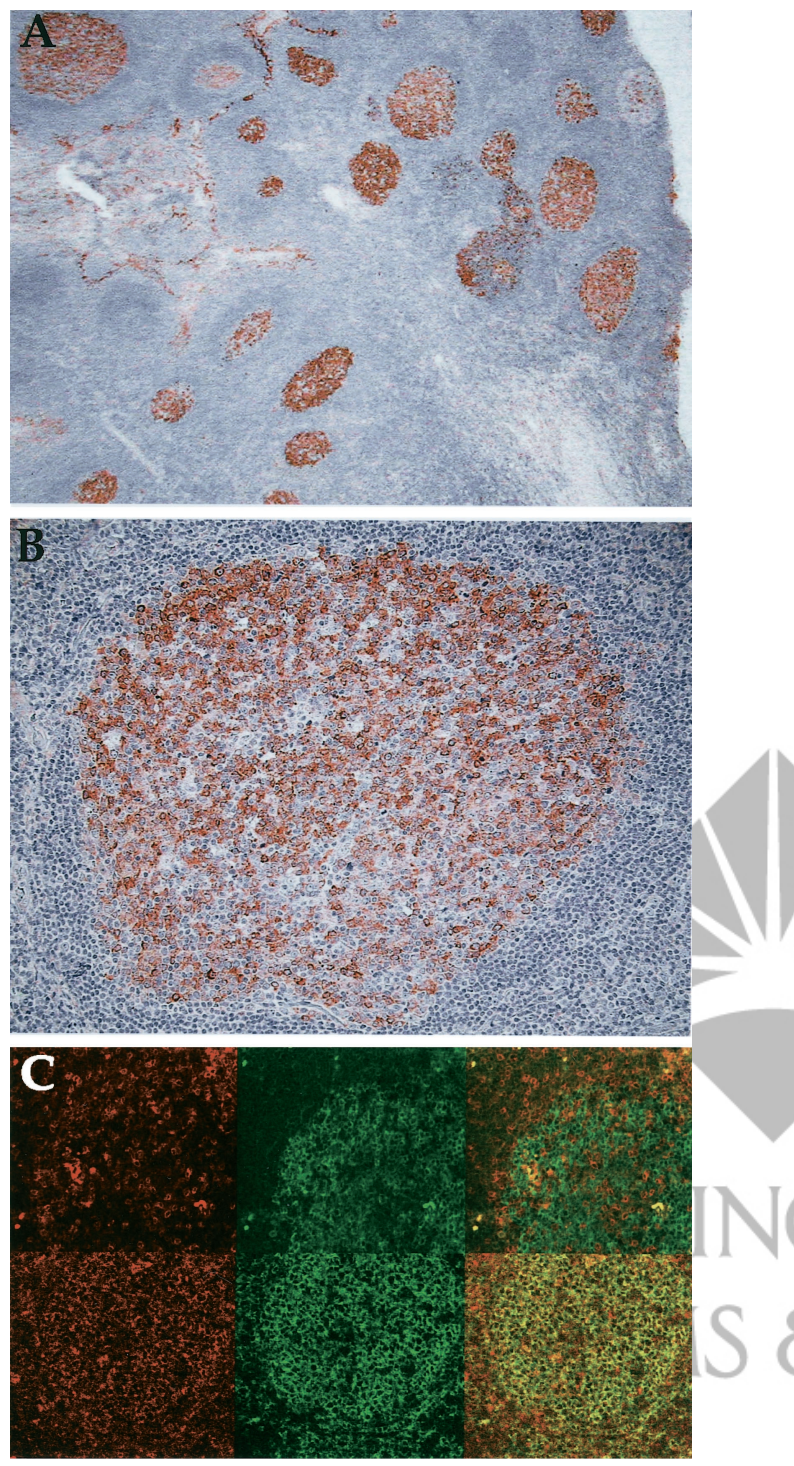

Figure 4.

$\mathrm{A}$ and $\mathrm{B}$, Immunostaining of human tonsillar tissue with $\mathrm{hMG}$ Ab. Strong immunostaining was observed in most of the follicular center cells. Tonsillar epithelial cells were moderately stained. C, Double-labeling immunofluorescence study of human tonsillar tissue with rabbit-derived hMG Ab (green) and murine-derived anti-CD3 (PS1) or CD20 (L26) (red). Upper left, Anti-CD3; upper middle, hMG Ab; upper right, Double-labeling of anti-CD3 and hMG Ab; lower left, Anti-CD20; lower middle, hMG Ab; lower right, Double-labeling of CD20 and hMG Ab. Very obvious colocalization of MetAP2 with CD20, but not with $\mathrm{CD} 3$, is observed.

in 26 of 150 B-cell lymphomas but not in any of the T-cell lymphomas or Hodgkin's lymphoma. Weak immunostaining, categorized as + , was observed in 67 of 150 B-cell lymphomas, in 14 of 40 T-cell lymphomas, and in Reed-Sternberg cells of 10 of 10 cases of Hodgkin's lymphoma. When these results were examined more closely according to subtype, the expression in B-cell lymphoma subtypes correlated well with their putative normal counterparts: ++ or + level immunostaining in 14 (88\%) of 16 cases of follicular lymphomas, $71(71 \%)$ of 100 cases of diffuse large B-cell lymphoma, and 3 of 3 cases of Burkitt's lymphoma (Fig. 5). All cases of ++ level immunostaining
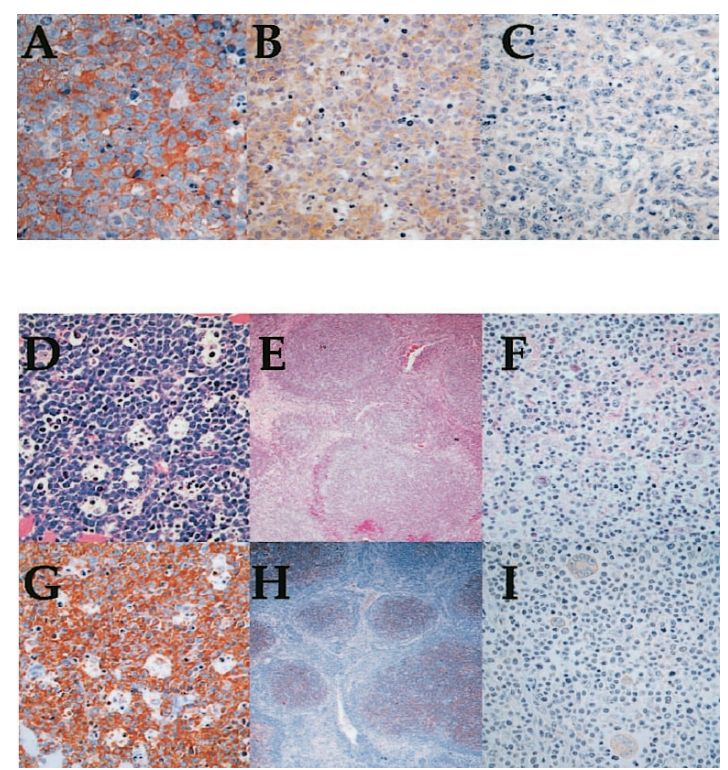

Figure 5.

Representative human lymphoma tissues stained with hMG Ab. A, Diffuse large B-cell lymphoma (DLB) with intense (++ level) MetAP2 staining. B, DLB with weak (+ level) MetAP2 staining. C, DLB with very faint (- level) MetAP2 staining. D and G, Burkitt's Iymphoma. E and H, Follicular lymphoma. F and I, Hodgkin's lymphoma. D, E, and F, Hematoxylin and eosin staining; G, H, and I, Immunostaining with hMG Ab.

were included in those subtypes. Meanwhile, the incidence of immunostained cases was low in other B-cell lymphoma subtypes, including mantle cell lymphoma, mucosa-associated lymphoid tissue lymphoma, nodal marginal zone lymphoma, and plasma cell lymphoma: No ++ level immunostaining was noted in those subtypes, and + level immunostaining was observed in $0(0 \%)$ of 3 cases of B-cell chronic lymphocytic leukemia, 1 (14\%) of 7 cases of mucosaassociated lymphoid tissue lymphoma, 1 (17\%) of 6 cases of nodal marginal zone B-cell lymphoma and 0 $(0 \%)$ of 3 cases of plasma cell lymphoma.

Among T-cell lymphoma subtypes, + level immunostaining was observed in $4(27 \%)$ of 15 cases of precursor T-lymphoblastic lymphoma, 1 (100\%) of 1 case of mycosis fungoides, $2(25 \%)$ of 8 cases of peripheral T-cell lymphoma, $0(0 \%)$ of 8 cases of angioimmunoblastic T-cell lymphoma, 1 (100\%) of 1 case of adult T-cell leukemia/lymphoma, and 6 (100\%) of 6 cases of anaplastic large cell lymphoma. Hodgkin's/Reed-Sternberg cells were + positive in all cases of Hodgkin's lymphoma (10/10, 100\%; Fig. 5).

\section{Correlation of MetAP2 Expression with that of BCL6, CD10, and BCL2 in Diffuse Large B-Cell Lymphoma (DLB)}

BCL6 protein is currently regarded as the most specific marker of germinal center B cells and their neoplastic counterparts. Since the results described herein suggest that MetAP2 is also expressed specifically in germinal center B cells, our next aim was to establish whether the expression of both proteins correlated. Thus, the expressions of MetAP2 and BCL6 were analyzed for correlation in 50 cases of 
Table 1. Expression of Methionine Aminopeptidase Type 2 Protein in Nonneoplastic Tissues

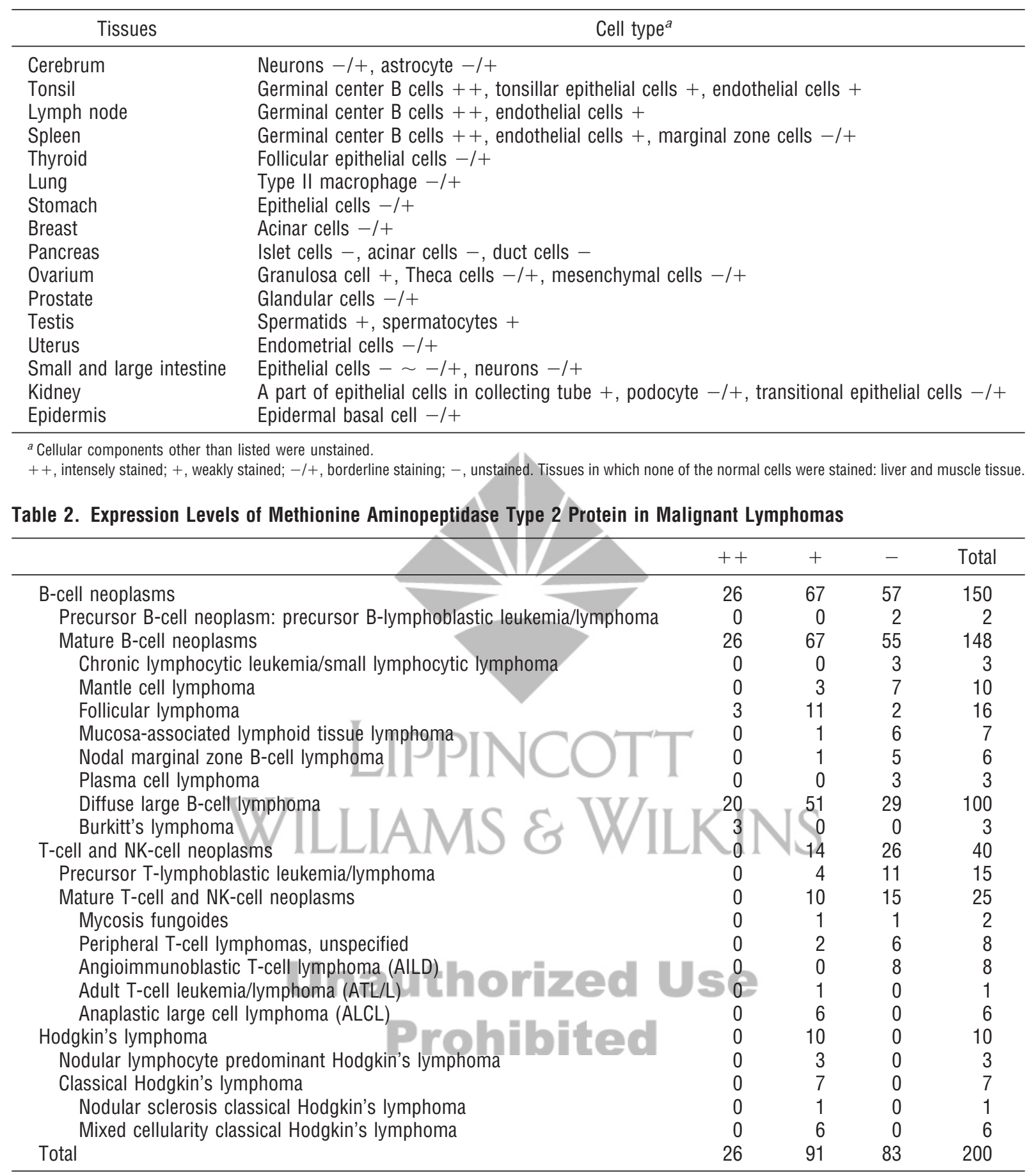

NK, natural killer.

DLB. MetAP2 immunoreactivity was demonstrated in 36 cases $(++$ level reaction in 9/50 [18\%], + level in 27/50 [54\%]) and BCL6 immunoreactivity was demonstrated in 45 cases (++ level reaction in 10/50 [20\%], + in 35/50 [70\%]). After statistical analysis, the expression of MetAP2 and BCL6 correlated $(p=$ 0.0275; Fisher's exact probability test) (Table 3). In addition, we studied the association between MetAP2 and CD10, another germinal center B-cell marker, but no statistically significant correlation was observed.
Similarly, no association was noted between the expression of MetAP2 and BCL2 in these DLB cases.

\section{Discussion}

This study was initially undertaken to examine the expression of MetAP2 protein in various human tissues and malignancies. Two antibodies (hMG and hMP Abs) reacting with different epitopes were raised in rabbits using recombinant MetAP2 protein (hMG 
Table 3. Correlation in Expression of Methionine Aminopeptidase Type 2 with BCL-6 and BCL-2 in 50 Diffuse Large B-cell Lymphomas

\begin{tabular}{lcccccc}
\hline & BCL6 $(++,+)$ & BCL6 $(-)$ & & BCL2 $(++,+)$ & BCL2 $(-)$ \\
\hline MetAP2 $(++,+)$ & 35 & 1 & 36 & 28 & 8 & 36 \\
MetAP2 $(-)$ & 10 & 4 & 14 & 12 & 2 & 14 \\
Total & 45 & 5 & 50 & 40 & 10 & 50 \\
& $(p=0.0275$ on Fisher's exact test $)$ & $(p=0.421$ on Fisher's exact test $)$ \\
\hline
\end{tabular}

Ab) and synthetic peptide (hMP Ab). Detailed control studies (immunoprecipitation, immunoblotting, and immunohistochemistry) confirmed that both Abs react specifically with MetAP2 protein. In a subsequent immunohistologic study on various human tissues, we found unexpectedly strong and selective expression in normal germinal center B cells. There were some other cells that were stained weakly or at a borderline low level (Table 1), whereas the staining of germinal center $B$ cells was far more intense than those cells. Such high expression of MetAP2 in germinal center B cells is an entirely novel finding.

The MetAP2 protein has been ascribed two functions: processing of the $\mathrm{N}$-terminal methionine residue and protection of elF2- $\alpha$ from inhibitory phosphorylation by elF2 kinases. However, these functions do not explain the heavy and selective expression of MetAP2 in germinal center B cells, because none of the highly mitotic epithelial cells (ie, epidermal basal cells, gastric foveolar cells, and intestinal epithelium) and none of the cells that are involved in the differentiation process (ie, suprabasal keratinocytes in the epidermis) exhibit such high expression. Rather, it is more likely that the MetAP2 protein participates in some unique function of the germinal center B cells. An interesting article, which might somehow relate to this observation, was published recently by Catalano et al (2001) in which it was demonstrated that high expression of MetAP2 is observed in human mesothelioma tissue, and its high expression is associated with antiapoptotic function in those neoplastic cells. These authors showed that the inhibition of MetAP2 expression in mesothelioma cells leads to cell death and that such apoptosis is avoided in cases where there is overexpression of BCL2. These results may give some credence to the speculation that a similar MetAP2 mechanism is working in germinal center B cells. However, applying the same mechanism in germinal center $B$ cells is rather difficult because germinal center B cells have low BCL2 expression and are highly apoptotic despite high MetAP2 expression. In addition, no clear association was noted between MetAP2 and BCL2 expression in the lymphoma cases studied so far. Further studies will be needed to establish the functional significance of MetAP2 in germinal center B cells. There is another interesting article reporting that experimental administration of the angiogenesis inhibitor TNP-470, which is known to be a specific inhibitor of MetAP2, caused enlargement of murine germinal centers (Antoine et al, 1996). To our knowledge, this is the only other published work in which the relationship between MetAP2 and the germinal center is considered. Further studies of this work would aid in the interpretation of the present results. Pharmacoimmunologic studies as well as molecular/pathologic studies of MetAP2 may help to elucidate the relationship between MetAP2 and germinal center $\mathrm{B}$ cells.

Lymphoma cells that share a germinal center $B$ cell phenotype have been shown in this study to express high amounts of MetAP2. Furthermore, we demonstrated that the expression of MetAP2 is associated with BCL6, a molecular marker for germinal center B cells (Onizuka et al, 1995). Thus, it is highly likely that DLBs expressing high levels of MetAP2 are the neoplastic counterparts of germinal center B cells. The usefulness of BCL6 expression as a marker for germinal center B cells should not be overestimated, however, because the expression of BCL6 can be low when gene disruption occurs after chromosomal translocation (Onizuka et al, 1995). Similarly, even though the results of the present study confirmed clearly that MetAP2 is a marker of germinal center B cells, care should be exercised when this concept is applied to neoplasms. Indeed, at this moment there is no evidence to suggest that MetAP2 is associated with lymphomagenesis. However there are a few case reports of follicular lymphomas and DLBs that carry abnormalities in 12q22, the chromosomal locus of the MetAP2 gene (http://cgap.nci.nih.gov/Chromosomes/ MitelSearch). The analysis of MetAP2 expression in such cases might be worthy of study in the future.

\section{Materials and Methods}

\section{Cells and Pathology Specimens}

Normal peripheral blood mononuclear cells were obtained from authors T. K. and S. M. by the density gradient method. 293T cells, derived from human kidney epithelial cells, the Burkitt's lymphoma cell lines Ramos and Daudi, and the precursor non-T non-B lymphoblastic lymphoma cell lines Nalm6 and Nall1 cells, were also used. A portion of cells was fixed with $10 \%$ formaldehyde and embedded in paraffin to make cell blocks for immunostaining. The remaining portion was used for immunoprecipitation and immunoblotting. Pathology specimens used in this study consisted of nonneoplastic human tissues including tonsils, lymph nodes, spleens, and other organs including brain, thyroid, skin, lung, stomach, small and large intestine, breast, uterus, muscle, kidney, liver, pancreas, testis, ovary, and prostate, which were derived from normal portions of surgically resected pathology specimens. Two hundred cases of lympho- 
mas of various subtypes were also studied. Immunostained slides were made for routine diagnosis, and hematoxylin and eosin-stained slides were used to confirm the diagnosis.

\section{Production of Recombinant MetAP2 Protein}

First-strand cDNA was synthesized from total RNA extracted from peripheral blood mononuclear cells by the use of a T-primed First-Strand cDNA synthesis kit (Ready To Go, Amersham Pharmacia Biotech, Uppsala, Sweden). The C-terminal region of MetAP2 cDNA, corresponding to amino acid residues 224 to 478, was PCR-amplified from the first-strand total cDNA by using forward primer, 5'-GCCGAATTCTCTCTCAATAATTGTGCTGCCC-3', and reverse primer, 5'-GAGCTCGAGTTAATAGTCATCTCCTCTGCTGAC-3'. The PCR product, designated hM224-478, was digested at the EcoRI and $\mathrm{Xhol}$ sites and inserted into the pGEX-5X-1 vector (Amersham Pharmacia Biotech) so that inserted hM224$478 \mathrm{cDNA}$ fused with glutathione S-transferase (GST) cDNA to produce the GST-hM224-478 fusion protein. This recombinant fusion protein was then expressed in E. coli and purified by the use SDS-PAGE.

\section{Abs}

Two anti-MetAP2 Abs reacting with different epitopes were developed in rabbits. First, rabbits were immunized with purified GST-hM224-478 protein. The immune sera were partially purified by ammonium sulfate, precleared by passage through GST-Sepharose columns to absorb anti-GST Abs, and purified thereafter with a GST-hM224-478 blotted membrane. This $A b$ was termed hMG Ab. Another Ab, termed hMP Ab, was made by immunizing synthetic peptides corresponding to amino acids 135 to 150 of human MetAP2 (hM135-150). The immune sera were affinity purified with antigen columns on which hM135-150 was coupled to 2-fluoro-1-methylpyridinium toluene-4-sulfonate (FMP)activated cellulofine (Seikagaku Company, Tokyo, Japan).

Other primary Abs used in this study consisted of anti-BCL6 (DAKO Japan, Kyoto, Japan), anti-CD3 (PS1; Novocastra Laboratories Ltd., Newcastle, United Kingdom), and anti-CD20 (DAKO Japan). For the second-step reagents of immunoperoxidase staining, peroxidase-labeled anti-murine IgG (Nichirei, Tokyo, Japan) and anti-rabbit peroxidase-labeled IgG (Nichirei) were used. For immnofluoro double labeling, donkey anti-rabbit IgG conjugated with fluorescein (Amersham Pharmacia Biotech) and sheep antimouse IgG conjugated with Texas Red (Amersham Pharmacia Biotech) were used.

\section{Immunoprecipitation and Immunoblotting}

Immunoprecipitation and immunoblotting were performed to confirm the specificities of two anti-MetAP2 Abs. First, Ramos, Daudi, Nall1, and Nalm6 cells were lysed in SDS-modified RIPA buffer. The lysates were boiled for 5 minutes, placed on ice for 5 minutes, and centrifuged at $15,000 \mathrm{rpm}$ at $4^{\circ} \mathrm{C}$ for 20 minutes. The supernatants were incubated with anti-MetAP2 Abs at $4^{\circ} \mathrm{C}$ overnight. Immune complexes thus obtained were absorbed to protein G-Sepharose (Amersham Pharmacia Biotech) and washed thoroughly with SDS-modified RIPA buffer. The immunoprecipitates were boiled with Laemmli's sample buffer and then separated electrophoretically on SDS (10\% wt/vol)-polyacrylamide gel. The samples were transferred to a polyvinylidene difluoride membrane (Millipore, Bedford, Massachusetts), and incubated with affinity-purified hMP or hMG Ab. The filter was washed thoroughly and incubated with alkaline phosphatase-conjugated anti-rabbit IgG (Promega KK, Tokyo, Japan). Then, the filter was stained with 5-bromo-4-chloro-3-indolylphosphate $p$-toluidine salt and nitroblue tetrazolium chloride, according to the manufacturer's instructions (Promega KK). MetAP2 224-478 fusion protein-expressing 293T cells, described below, were treated similarly for immunoprecipitation and immunoblotting.

\section{Transient Expression of FLAG-Human MetAP2 224-478 Fusion Protein}

This study was conducted for further confirmation of the Ab specificity. A DNA fragment corresponding to the C-terminal region (amino acid residues 224-478) (described above) was cloned into the expression vector pME18SFLAG. The expression vector was transfected into 293T cells using Lipofectin reagent (Gibco BRL Co., Grand Island, New York). After 48 hours, cells were harvested and a portion was fixed with $10 \%$ formaldehyde to make cell blocks, followed by immunostaining. The remaining portion was used for immunoprecipitation and immunoblotting.

\section{Immunohistochemistry \\ Paraffin-embedded nonneoplastic human tissues, cell} blocks, and lymphoma biopsy specimens were studied for the expression of MetAP2 by immunohistochemistry with the use of two anti-MetAP2 Abs, hMG and hMP. For antigen retrieval, deparaffinized sections were autoclaved in a $10 \mathrm{mmol} / \mathrm{L}$ citrate buffer at pH 6.0 for 15 minutes and allowed to cool for an additional 60 minutes at room temperature. Sections were then incubated with blocking reagents, first Abs, followed by secondary reagents. Diaminobenzidine tetrahydrochloride was used for chromogen. Negative controls were run with the preimmunized rabbit's serum diluted appropriately. The immunohistopathologic results were evaluated as ++ , intensely stained; + , weakly stained; - , very faintly stained or unstained. Examples of staining intensity are shown in the figures. The expression of BCL6 protein was also studied immunohistochemically on tonsil and 50 DLBs and correlated with the results of anti-MetAP2 Abs.

\section{Double-Labeling Immunofluorescence Study}

Paraffin sections of nonneoplastic tonsils were subjected to indirect immunofluorescence to assess the character of cells expressing MetAP2. Double labeling was conducted by the use of rabbit-derived $h M G A b$ and murine-derived anti-CD3 or anti-CD20. After an- 
tigen retrieval and incubation with blocking reagents, sections were incubated with a mixture of hMG Ab and anti-CD3 or anti-CD20. They were rinsed and incubated with a mixture of donkey anti-rabbit IgG conjugated with fluorescein (Amersham Pharmacia Biotech) and sheep anti-mouse IgG conjugated with Texas Red (Amersham Pharmacia Biotech). The sections were examined using confocal laser microscopy (RTS2000; Bio-Rad, Hercules, California).

\section{Histopathologic Diagnosis of Lymphomas}

Hematoxylin and eosin-stained and immunostained slides of two hundred lymphoma cases were reviewed by three pathologists (T. K., K. T., S. M.). Consensus diagnosis was obtained through discussion by those members when disagreement was noted. The REAL classification (Harris et al, 1994) and the new WHO classification (Jaffe et al, 2001) was introduced for the subclassification of lymphomas.

\section{Acknowledgement}

We thank Dr. Shinobu Imajoh-Ohmi for helpful suggestions on antibody production.

\section{References}

Antoine N, Daukandt M, Heinen E, Simar LJ, and Castronovo $V$ (1996). In vitro and in vivo stimulation of the murine immune system by AGM-1470, a potent angiogenesis inhibitor. Am J Pathol 148:393-398.

Arfin SM, Kendall RL, Hall L, Weaver LH, Stewart AE, Matthews BW, and Bradshaw RA (1995). Eukaryotic methionyl aminopeptidases: Two classes of cobalt-dependent enzymes. Proc Natl Acad Sci U S A 92:7714-7718.

Ben-Bassat A, Bauer K, Chang SY, Myambo K, Boosman A, and Chang S (1987). Processing of the initiation methionine from proteins: Properties of the Escherichia coli methionine aminopeptidase and its gene structure. J Bacteriol 169:751757.

Bradshaw RA, Brickey WW, and Walker KW (1998). $\mathrm{N}$-terminal processing: The methionine aminopeptidase and $\mathrm{N}$ alpha-acetyl transferase families. Trends Biochem Sci 23:263-267.

Catalano A, Romano M, Robuffo I, Strizzi L, and Procopio A (2001). Methionine aminopeptidase-2 regulates human mesothelioma cell survival: Role of $\mathrm{Bcl}-2$ expression and telomerase activity. Am J Pathol 159:721-731.

Chang YH, Teichert U, and Smith JA (1992). Molecular cloning, sequencing, deletion, and overexpression of a methionine aminopeptidase gene from Saccharomyces cerevisiae. J Biol Chem 267:8007-8011.

Datta B (2000). MAPs and POEP of the roads from prokaryotic to eukaryotic kingdoms. Biochimie 82:95-107.

Datta B, Chakrabarti D, Roy AL, and Gupta NK (1988). Roles of a $67-\mathrm{kDa}$ polypeptide in reversal of protein synthesis inhibition in heme-deficient reticulocyte lysate. Proc Natl Acad Sci U S A 85:3324-3328.

Endo H, Takenaga K, Kanno T, Satoh H, and Mori S (In press, 2002). Methionine aminopeptidase 2 is a new target for the metastasis-associated protein S100A4. J Biol Chem.
Flinta C, Persson B, Jornvall H, and von Heijne G (1986). Sequence determinants of cytosolic $\mathrm{N}$-terminal protein processing. Eur J Biochem 154:193-196.

Golay J, Broccoli V, Lamorte G, Bifulco C, Parravicini C, Pizzey A, Thomas NS, Delia D, Ferrauti P, Vitolo D, and Introna M (1998). The A-Myb transcription factor is a marker of centroblasts in vivo. J Immunol 160:2786-2793.

Griffith EC, Su Z, Turk BE, Chen S, Chang YH, Wu Z, Biemann K, and Liu JO (1997). Methionine aminopeptidase (type 2) is the common target for angiogenesis inhibitors AGM-1470 and ovalicin. Chem Biol 4:461-471.

Harris NL, Jaffe ES, Stein H, Banks PM, Chan JK, Cleary ML, Delsol G, De Wolf-Peeters C, Falini B, and Gatter KC (1994). $A$ revised European-American classification of lymphoid neoplasms: A proposal from the International Lymphoma Study Group [see comments]. Blood 84:1361-1392.

Jackson R and Hunter T (1970). Role of methionine in the initiation of haemoglobin synthesis. Nature 227:672-676.

Jaffe ES, Harris NL, Stein H, Vardiman JW (2001). World Health Organization classification of tumours: Pathology and genetics: Tumours of hematopoietic and lymphoid tissues. Lyon, France: IARC Press.

Kerwar SS, Weissbach H, and Glenner GG (1971). An aminopeptidase activity associated with brain ribosomes. Arch Biochem Biophys 143:336-337.

Kimball SR (1999). Eukaryotic initiation factor elF2. Int J Biochem Cell Biol 31:25-29.

Kuppers R, Klein U, Hansmann ML, and Rajewsky K (1999). Cellular origin of human B-cell lymphomas. N Engl $\mathrm{J}$ Med 341:1520-1529.

Li X and Chang YH (1995a). Amino-terminal protein processing in Saccharomyces cerevisiae is an essential function that requires two distinct methionine aminopeptidases. Proc Natl Acad Sci U S A 92:12357-12361.

Li X and Chang YH (1995b). Molecular cloning of a human complementary DNA encoding an initiation factor 2-associated protein (p67). Biochim Biophys Acta 1260:333-336.

Li X and Chang YH (1996). Evidence that the human homologue of a rat initiation factor-2 associated protein (p67) is a methionine aminopeptidase. Biochem Biophys Res Commun 227:152-159.

Liu S, Widom J, Kemp CW, Crews CM, and Clardy J (1998). Structure of human methionine aminopeptidase-2 complexed with fumagillin. Science 282:1324-1327.

Lowther WT and Matthews BW (2000). Structure and function of the methionine aminopeptidases. Biochim Biophys Acta 1477:157-167.

MacLennan IC (1994). Germinal centers. Annu Rev Immunol 12:117-139.

Martinez-Valdez H, Guret C, de Bouteiller O, Fugier I, Banchereau J, and Liu YJ (1996). Human germinal center B cells express the apoptosis-inducing genes Fas, c-myc, P53, and Bax but not the survival gene bcl-2. J Exp Med 183:971-977.

McHeyzer-Williams LJ, Driver DJ, and McHeyzer-Williams MG (2001). Germinal center reaction. Curr Opin Hematol 8:52-59.

Movva NR, Semon D, Meyer C, Kawashima E, Wingfield P, Miller JL, and Miller CG (1990). Cloning and nucleotide sequence of the Salmonella typhimurium pepM gene. Mol Gen Genet 223:345-348. 
Onizuka T, Moriyama M, Yamochi T, Kuroda T, Kazama A, Kanazawa N, Sato K, Kato T, Ota H, and Mori S (1995). BCL-6 gene product, a 92- to 98-kD nuclear phosphoprotein, is highly expressed in germinal center B cells and their neoplastic counterparts. Blood 86:28-37.

Pestova TV, Kolupaeva VG, Lomakin IB, Pilipenko EV, Shatsky IN, Agol VI, and Hellen CU (2001). Molecular mechanisms of translation initiation in eukaryotes. Proc Natl Acad Sci U S A 98:7029-7036.

Schubart DB, Rolink A, Kosco-Vilbois MH, Botteri F, and Matthias P (1996). B-cell-specific coactivator OBF-1/OCA-B/ Bob1 required for immune response and germinal centre formation. Nature 383:538-542.
Sin N, Meng L, Wang MQ, Wen JJ, Bornmann WG, and Crews CM (1997). The anti-angiogenic agent fumagillin covalently binds and inhibits the methionine aminopeptidase, MetAP-2. Proc Natl Acad Sci U S A 94:6099-6103.

Wigle DT and Dixon GH (1970). Transient incorporation of methionine at the $\mathrm{N}$-terminus of protamine newly synthesized in trout testis cells. Nature 227:676-680.

Zhang Y, Griffith EC, Sage J, Jacks T, and Liu JO (2000). Cell cycle inhibition by the anti-angiogenic agent TNP-470 is mediated by p53 and p21WAF1/CIP1. Proc Natl Acad Sci U S A 97:6427-6432.

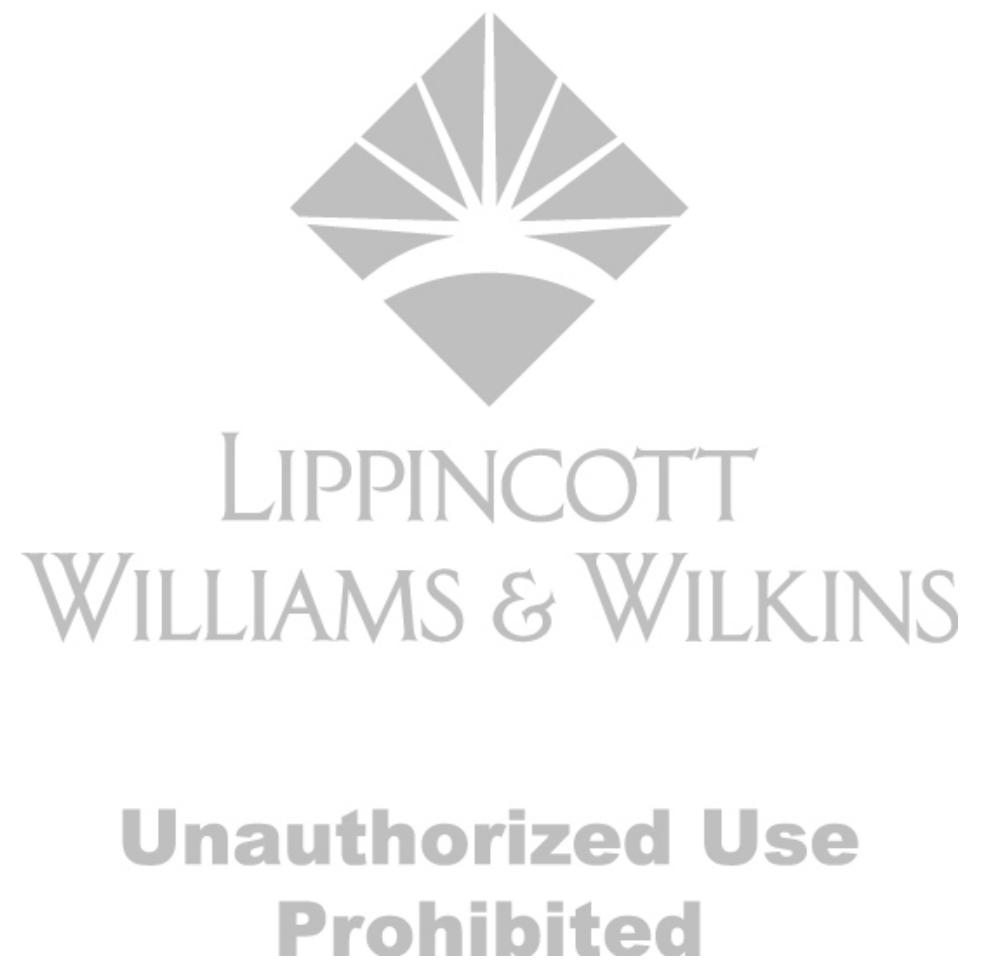

